Swarthmore College

Works

$5-14-2021$

\title{
Social Communication Across Reproductive Boundaries: Hormones And The Auditory Periphery Of Songbirds And Frogs
}

\author{
M. D. Gall
}

Alexander T. Baugh

Swarthmore College, abaugh1@swarthmore.edu

J. R. Lucas

M. A. Bee

Follow this and additional works at: https://works.swarthmore.edu/fac-biology

Part of the Biology Commons

Let us know how access to these works benefits you

\section{Recommended Citation}

M. D. Gall, Alexander T. Baugh, J. R. Lucas, and M. A. Bee. (2021). "Social Communication Across Reproductive Boundaries: Hormones And The Auditory Periphery Of Songbirds And Frogs". Integrative And Comparative Biology. DOI: 10.1093/icb/icab075

https://works.swarthmore.edu/fac-biology/624

This work is brought to you for free by Swarthmore College Libraries' Works. It has been accepted for inclusion in Biology Faculty Works by an authorized administrator of Works. For more information, please contact myworks@swarthmore.edu. 
Title: Social communication across reproductive boundaries: hormones and the auditory periphery of songbirds and frogs

Title: Hormones, the auditory periphery, and social communication

\author{
Megan D. Gall ${ }^{1 \dagger}$, Alexander T. Baugh ${ }^{2}$, Jeffrey R. Lucas ${ }^{3}$, Mark A. Bee 4,5 \\ ${ }^{1 \dagger}$ Department of Biology, Vassar College, 124 Raymond Ave, Poughkeepsie, NY, 12604, USA \\ ${ }^{2}$ Department of Biology, Swarthmore College, 500 College Avenue, Swarthmore, PA, 19081, \\ USA
}

${ }^{3}$ Department of Biological Sciences, Purdue University, West Lafayette, IN 65203

${ }^{4}$ Department of Ecology, Evolution, and Behavior, University of Minnesota, 1479 Gortner Ave, St. Paul, MN, 55108, USA

${ }^{5}$ Graduate Program in Neuroscience, University of Minnesota, 321 Church Street SE, Minneapolis, MN, 55455, USA

†Corresponding Author email: megall@vassar.edu, phone: 845-437-7115

\title{
Acknowledgements:
}

We would like to acknowledge the contributions of Walter Wilczynski to the field, as well as his mentorship and inspiration. Funding was provided by an NSF doctoral dissertation improvement grant (IOS-1109677), an Animal Behavior Society graduate student research award, the Society for Integrative and Comparative Biology, and the Company of Biologists. All experiments were approved under Purdue IACUC \# 1111000125.

(C) The Author(s) 2021. Published by Oxford University Press on behalf of the Society for Integrative and Comparative Biology. All rights reserved. For permissions please email: journals.permissions@oup.com. 


\section{ABSTRACT}

Most animals experience reproductive transitions in their lives; for instance, reaching reproductive maturity or cycling in and out of breeding condition. Some reproductive transitions are abrupt, while others are more gradual. In most cases, changes in communication between the sexes follow the time course of these reproductive transitions and are typically thought to be coordinated by steroid hormones. We know a great deal about hormonal control of communication behaviors in birds and frogs, as well as the central neural control of these behaviors. There has also been significant interest in the effects of steroid hormones on central nervous system structures that control both the production and reception of communication signals associated with reproductive behaviors. However, peripheral sensory structures have typically received less attention, although there has been growing interest in recent years. It is becoming clear that peripheral sensory systems play an important role in reproductive communication, are plastic across reproductive conditions, and, in some cases, this plasticity may be mediated by steroid hormones. In this paper, we discuss recent evidence for the role of peripheral auditory structures in reproductive communication in birds and frogs, the plasticity of the peripheral auditory system, and the role of steroid hormones in mediating the effects of the peripheral auditory system on reproductive communication. We focus on both seasonal and acute reproductive transitions, introduce new data on the role of hormones in modulating seasonal patterns, and make recommendations for future work.

Keywords: seasonality, reproduction, communication, hearing, anurans, birds 


\section{INTRODUCTION}

Communication systems show seasonal plasticity (within-individual variation in behavior or physiology, irrespective of the possible functional implications of that variability) in many seasonally breeding animals. This within-individual plasticity is evidenced in both the production and reception of communication signals (songbirds: Catchpole and Slater 2008; fish: Webb et al. 2008; frogs: Ryan 2001). Temperate songbirds and frogs have served as the two main models for investigations of vocal communication. In these taxa, male production of mate attraction vocalizations increases during the breeding season and is accompanied by hormonal and neural changes (Kroodsma and Miller 1982; Itoh and Ishii 1990). Female responses to male vocalizations in both birds and frogs also show plasticity and are tightly correlated with current reproductive condition (Arch and Narins 2009; Maney and Pinaud 2011). Animals can also experience acute reproductive transitions, such as those associated with oviposition, where females rapidly ( $<24$ hours) transition from a breeding to a non-breeding condition. These transitions are often accompanied by dramatic changes in the receptivity of females to male communication signals (Lynch et al. 2005; Gall et al. 2019). Mounting evidence suggests that these behavioral changes are accompanied by plasticity in peripheral auditory processing in birds and frogs (Lucas et al. 2002; 2007; Henry and Lucas 2009; Caras et al. 2010; Zhang et al. 2012; Gall et al. 2013). However, our understanding of the mechanisms responsible for these reproductively-related changes in auditory processing is relatively limited. The role of steroid hormones in modulating other aspects of communication, as well as a strong body of work in midshipman and cichlid fish, suggests that steroid hormones may be implicated in modulating peripheral auditory processing (Forlano et al. 2016). In this review, we discuss the current evidence for plasticity in peripheral auditory processing across seasonal and acute reproduction 
transitions. We focus primarily on songbirds and frogs, the role of steroid hormones in modulating this plasticity (including new data on recapitulation of seasonal patterns by exogenous steroid hormones), and possible mechanisms through which hormones may influence auditory processing.

Our review covers three aspects of peripheral auditory processing: sensitivity, frequency selectivity and temporal resolution. Sensitivity can be described by either the lowest amplitude signal that can be detected (e.g. threshold) or the magnitude of the response to signals above this threshold. Frequency selectivity, which can be measured in a number of ways, represents the ability of the peripheral auditory system to discriminate between two tones close together in frequency. Finally, temporal resolution, which can again be measured in many ways, describes the ability of the auditory system to discriminate between two sounds that are close together in time or the ability to follow rapid temporal fluctuations in sounds. Together, these parameters play a role in an animal's ability to detect and discriminate among communication signals and are likely important in determining the salience of these signals.

\section{SEASONAL AND HORMONE-MEDIATED PLASTICITY IN PERIPHERAL AUDITORY PROCESSING}

Seasonal differences in the auditory periphery of songbirds

An understanding of the plasticity in auditory processing has the potential to fundamentally change our understanding of communication, particularly with respect to what information is extracted from signals, how that information is extracted, and the functional implications of changes in information processing. Seasonal variation in the auditory periphery of birds was first reported by Lucas et al. in 2002 when they found species-specific seasonal changes in the response amplitude of auditory evoked potentials to broadband clicks in three 
species that form mixed-species flocks during the fall and winter. Specifically, white-breasted nuthatches (Sitta carolinensis) had greater response amplitudes (i.e. sensitivity) in the winter and Carolina chickadees (Poecile carolinensis) and tufted titmice (Baeolophus bicolor) had greater sensitivity in the spring. Subsequent studies of these three species found similar patterns in the processing of the onsets and sustained portions of tones, as well as temporally modulated signals (Lucas 2007; Velez et al. 2015). These results suggest that auditory processing abilities reflect seasonal changes in the types and information content of vocalizations. Velez et al. (2015) found that seasonal processing of both temporally modulated signals and the fine structure of tones was sex-specific in chickadees and titmice, suggesting that it may be of particular importance for mate choice in females. Songs in both of these species tend to be tonal whereas the call system consists of more complex elements - patterns that match season-specific changes in auditory processing. Additionally, Henry and Lucas (2009) found that house sparrows (Passer domesticus) showed seasonal differences in their frequency sensitivity, with the greatest effects at and above $2 \mathrm{kHz}$, in the frequency range of male vocalizations. While these studies demonstrated seasonal differences in auditory processing, the mechanisms generating these differences were not investigated.

\section{Evidence for steroid hormone effects in the avian auditory periphery}

There has been ample speculation that steroid hormones are involved in the peripheral auditory plasticity of songbirds, but little published work on the subject. The discovery of estrogen receptors and aromatase in the inner ear of zebra finches (Taeniopygia guttata, Noirot et al. 2009), suggests that estrogen (either circulating or locally synthesized from testosterone) potentially influences peripheral auditory function. However, only one published study has 
explicitly linked the level of circulating sex hormones to the peripheral processing of auditory stimuli in birds (See Caras et al. 2010). The authors found that white-crowned sparrows (Zonotrichia leucophrys), kept under induced-breeding conditions (i.e. implanted with either testosterone in males or estradiol in females and kept on a long-day light cycle), had auditory thresholds that were higher than birds kept in non-breeding condition (Caras et al. 2010). This study suggests a role for estrogen-mediated changes in the auditory periphery. However, it is difficult to extrapolate these results to naturally-occurring seasonal changes because no auditory threshold data are currently available for white-crowned sparrows in natural breeding and nonbreeding conditions. Furthermore, it is not clear whether steroid hormones are involved in the plasticity of other aspects of auditory processing in females, such as frequency selectivity or temporal resolution. Testosterone did not induce plasticity in frequency selectivity or temporal resolution in white-crowned sparrow males, and hormone-manipulated females were not tested for these traits (Caras et al. 2010).

Breeding condition induced by exogenous hormones can recapitulate seasonal patterns

Gall et al. (2013) previously demonstrated that the frequency selectivity (i.e. auditory filter bandwidths) and temporal resolution of the peripheral auditory system in house sparrows varies seasonally in a sex-specific manner (Figure 1). Specifically, they showed that female house sparrows have enhanced frequency resolution (auditory filter bandwidths narrowed) and diminished temporal resolution (as measured by response to paired clicks) in the breeding season relative to the non-breeding season, while males did not exhibit changes in their auditory processing. Previously unpublished work from two of the authors, Gall and Lucas, suggests that the reproductive condition induced by steroid hormones may play a role in this seasonal pattern. 
In the following section we will present the results from this previously unpublished work examining the relationship between exogenous hormone-induced reproductive condition on auditory plasticity, compare the results to the published work on natural seasonal patterns of auditory plasticity (Gall et al. 2013), and discuss these results in the context of the literature on house sparrow behavior and endocrinology. The goal of this study was not to determine the specific effects of estradiol, or testosterone, on auditory processing, but rather to recapitulate the seasonal transition in reproductive condition and auditory processing previously found in wild house sparrows. While the administration of hormones did successfully induce a reproductive condition, the hormone levels induced by the manipulation were somewhat different than those found in naturally breeding animals (see Table 1), thus care should be taken with the interpretation of the data, particularly for males. However, as they are currently the only data investigating whether hormone administration can recapitulate season patterns, we feel they are important to discuss.

Male and female house sparrows were captured in the non-breeding season and their frequency selectivity and temporal resolution was measured using auditory evoked potentials. Animals were then randomly assigned to a placebo or systemic hormone implant group (males: testosterone; females: $17 \beta$-estradiol), housed for three weeks on a 14:10 light cycle, and then retested for frequency selectivity and temporal resolution (See ESM for methodological details).

Implants were successful in elevating hormone levels. Testosterone levels increased in both placebo and testosterone males; however, the increase in testosterone was much greater in males given supplemental testosterone (Table 1). Estradiol levels were elevated in females that were given supplemental hormones but did not increase in females given a placebo implant (Table 1). Secondary sexual characteristics suggested that the hormone manipulation 
successfully brought the animals into breeding condition. All males given supplemental testosterone developed jet-black bills and showed a cloacal protuberance. Bill color in placebo birds ranged from horn to light black. In particular, the bills of males caught earlier in the season (October) did not appear to darken as much as males caught in November, which suggests that individuals with exposure to more short days are more physiologically responsive to the transition to long days in the lab. Males that received a placebo implant showed no sign of cloacal protuberance. All females given supplemental estrogen lost feathers from their lower abdomen (brood patch) while none of the females given a placebo implant lost feathers.

Perhaps more importantly, the hormone manipulations, and thus induced breeding condition, described here resulted in auditory plasticity that largely mirrored the natural seasonal variation Gall et al. (2013) had previously found, suggesting that breeding condition is linked to auditory processing. For frequency selectivity, both males and females with hormone implants showed greater frequency selectivity after treatment. Animals with placebo implants did not exhibit auditory plasticity (Figure 2). Moreover, there were no significant differences between the placebo and hormone groups prior to treatment; however, post-treatment animals with hormone implants had greater frequency selectivity than placebo animals. Temporal resolution mirrored seasonal changes even more closely. Placebo animals did not show plasticity, nor were there differences between the sexes. However, animals treated with hormones showed sexspecific responses, with no plasticity in males and a decrease in temporal resolution following hormone implantation in females (See ESM for full statistical model results).

Overall, we found that supplemental hormones that induced changes in reproductive condition could induce auditory plasticity over the course of three weeks. Increased photoperiod alone was insufficient to induce reproductive condition and did not result in an increase in 
frequency selectivity or a reduction in temporal resolution in the auditory system over the course of three weeks, while administration of supplemental hormones produced a reproductive condition and sex-specific plasticity in temporal resolution that matched natural sex-specific seasonal plasticity (Gall et al. 2013). However, the changes in frequency selectivity found here did not show the sex-specificity that we previously found in natural breeding populations. Previous cross-sectional data investigating natural seasonal variation in frequency selectivity suggested that frequency selectivity increases in females during the breeding season but does not change in males. In contrast, data reported herein suggest hormone-induced plasticity occurred in both sexes. It is possible that males treated with supplemental testosterone had a surfeit of testosterone, beyond the normal breeding levels, which permitted the peripheral auditory system to produce a greater amount of estradiol than would usually be produced, resulting in plasticity. Alternatively, the combination of hormone treatment and captive housing may have interacted to induce plasticity. Our data do not allow us to evaluate these hypotheses, which require further testing. Functionally, these changes in peripheral auditory processing may gate the salience of conspecific signals or make it easier for females to discriminate between conspecific and heterospecific signals, as estradiol has been shown to decrease responsiveness of central auditory processing areas to heterospecific signals (Lattin et al. 2017).

The patterns found here likely reflect the reproductive biology of house sparrows in temperate regions. Following the breeding season, house sparrows have a short non-breeding period (generally September - October) in which gonad development is photorefractory. During this time, individuals go through their prebasic molt (Anderson 2006). Photorefractoriness is broken after prebasic molt. House sparrows (males in particular) then enter a prolonged slow gonadal growth phase (Hegner and Wingfield 1986a-c) in which animals are sensitive to 
stimulatory photoperiods; however, animals are not fully reproductively active during this time. Following prebasic molt there is a small surge in gonadal steroid levels and the gonads begin a very slow increase in size (generally November - February) that is accompanied by increased nest site attendance by males. This increase in testosterone also triggers a slow increase in the darkness of male bills. As the spring equinox approaches there is a second and much larger spike in steroid hormones that initiates rapid growth of the gonads, after which animals are fully reproductively active.

In the fall and winter months, steroid hormone levels are still quite low, and, from a communication perspective, animals are primarily using signals in flocking, foraging and antipredator contexts. Housing animals caught immediately post-molt on a stimulatory photoperiod results in a slow increase in steroid hormones and gonadal growth, such that full reproductive condition would not be recovered in three weeks (Riley 1936; Anderson 2006). Indeed, although we found evidence of moderately elevated plasma testosterone in placebo males, we did not find an increase in estradiol levels in placebo females (as seen in Table 1). Furthermore, secondary sexual characteristics did not emerge (cloacal protuberance, brood patch) or show changes consistent with the breaking of photorefractoriness (bill color; Hegner and Wingfield 1986a-c). It may not be surprising, therefore, that auditory plasticity was not induced by a stimulatory photoperiod alone but was induced when exogenous hormones were supplied. However, we would expect that prolonged housing on a stimulatory light cycle would be sufficient to induce auditory plasticity, if longer exposure to a stimulatory light cycle was sufficient to increase circulating levels of gonadal steroids to reproductive levels. Seasonal and steroid-related changes in the auditory periphery of anurans 
There is perhaps even less evidence for seasonal changes in the auditory periphery of anuran amphibians. Zhang et al. (2012) found that frequency sensitivity was greater in the breeding season relative to the non-breeding season in Emei music frogs (Babina daunchina). However, frogs were all captured during the breeding season and held in captivity until the nonbreeding season, so it is difficult to determine whether the observed plasticity was due to breeding condition, captivity or both. In green treefrogs (Hyla cinerea), seasonal plasticity in peripheral auditory processing has not yet been documented. However, sensitivity to tones and to call-like stimuli masked by preceding calls increases in green treefrogs that have 10 days of experience with conspecific signals, but not random tones (Gall and Wilczynski 2015; 2016), suggesting the peripheral auditory system is plastic. This type of exposure to conspecific signals also elevates circulating levels of steroid hormones in several species of frogs (Wilczynski and Burmeister 2016), suggesting that hormones could play a role in this peripheral plasticity. Steroid hormones have been implicated in sex-specific peripheral auditory sensitivity to the spectral features of conspecific calls in African clawed frogs, Xenopus (Hall et al. 2016). Females in four species of Xenopus had greater peripheral sensitivity than males.

Ovariectomized X. laevis females had male-like tuning, while ovariectomized females treated with dihydrotesosterone retained female-like tuning. Although these results do not directly implicate steroid hormones in seasonal or reproductively-related plasticity, they do suggest that peripheral auditory tuning is sensitive to endocrine state in some frogs.

\section{ACUTE REPRODUCTIVE TRANSITIONS AND HORMONE-MEDIATED \\ PLASTICITY IN PERIPHERAL AUDITORY PROCESSING}

Although seasonal changes have been the primary focus of work on auditory plasticity, one of the most dramatic changes in behavioral responses to acoustic communication signals 
occurs during the rapid transition from a breeding to non-breeding condition that occurs following oviposition (Lynch et al. 2005; Gall et al. 2019). Following oviposition, female response to conspecific calls decreases dramatically. In the tropical túngara frog (Physalaemus pustulosus) both receptivity (i.e. likelihood of approaching an advertisement signal) and permissiveness (i.e. likelihood of approaching a heterospecific signal) increase dramatically at reproductive competence (Baugh and Ryan 2010) and decrease in post-mated females, although a small number of post-mated females continue to respond to male calls (Lynch et al. 2005). In the temperate Cope's gray treefrog (Hyla chrysoscelis) all post-mated females failed to respond to conspecific male calls or discriminate between conspecific and heterospecific calls (Gall et al. 2019). Similarly, circulating levels of gonadal and adrenal steroid hormones decline dramatically following breeding (Harvey et al. 1997; Lynch and Wilczynski 2005; Gall et al. 2019), which appears to cause rapid post mating behavior shifts. Based on these previous findings, it would be natural to predict that peripheral sensitivity should decrease following oviposition. However, in two recent studies of Cope's gray treefrogs, we found that peripheral auditory sensitivity was greater in post-oviposition females than in pre-oviposition females (Gall et al. 2019, Baugh et al. 2019). First, we found that post-oviposition females had lower threshold and greater suprathreshold responses to tonebursts designed to mimic the population average spectral components of conspecific calls (Gall et al. 2019). Circulating levels of estradiol, testosterone and corticosterone were also significantly lower in the post-oviposition females as compared to the pre-oviposition females. We found some evidence that circulating hormone levels were correlated with suprathreshold responses, but not thresholds. In particular, we found that in preoviposition females, suprathreshold sensitivity decreased with increasing levels of estradiol, while in post-oviposition females sensitivity increased with increasing levels of estradiol. This 
may suggest that there is a non-linear relationship between auditory sensitivity and circulating levels of estradiol, with intermediate levels leading to the greatest sensitivity. Second, we found frequency-specific changes in frequency sensitivity, with post-oviposition females being more sensitive than pre-oviposition females, particularly at frequencies corresponding to the amphibian papilla, one of the two sensory organs in the frog's inner ear sensitive to airborne sound (Baugh et al. 2019). Again, thresholds did not appear to be correlated with circulating levels of hormones, but we found that suprathreshold sensitivity was positively correlated with increasing levels of testosterone.

There are at least three explanations for these findings. First, both reproductive condition and circulating hormone level were included in the statistical model, so reproductive condition may explain some of the same variance in auditory sensitivity that is explained by circulating hormone levels. The second is that peripheral auditory sensitivity may vary in a non-linear or asymptotic manner that was not captured in our linear model. Finally, changes in peripheral processing associated with oviposition may not result from acute changes in circulating levels of steroid hormones. For instance, the changes we found are consistent with temporary threshold shifts resulting from high levels of noise (such as those encountered in a chorus environment) although anurans seem more resistant to this phenomenon than mammals (Zelick and Narins 1985; Penna and Narins 1989; Simmons et al. 2014). It is also possible that other hormones or neuromodulators may mediate these rapid changes in peripheral sensitivity. Pharmacological experiments, sound exposure experiments, or ideally a combination of both would allow us to further investigate these alternative hypotheses. Functionally, it is intriguing to consider the speculative hypothesis that these paradoxical results reflect an adaptive plasticity; for example, female auditory sensitivity during peak reproductive competence may be dampened because it 
mitigates against a hyper-stimulated proceptivity and resultant impulsivity during mate choice in favor of a more protracted mate sampling effort (c.f. sexual conflict).

\section{MECHANISMS THROUGH WHICH STEROID HORMONES MAY ALTER PERIPHERAL AUDITORY FUNCTION}

Steroid hormones may act directly on the auditory system to induce plasticity, or steroid hormones may act on auditory plasticity indirectly through some intermediate physiological mechanism. In frogs and songbirds, we do not yet have any experimental investigations of the mechanisms by which steroid hormones might mediate peripheral auditory plasticity. However, work on hormonally-mediated plasticity of the central auditory system of songbirds and frogs, as well as work on the hormonally-mediated plasticity of the peripheral auditory system of fish, suggest several possibilities.

In the central auditory system, estradiol can influence auditory function over several time scales (Caras and Remage-Healey 2016). Estradiol has rapid neuromodulatory function in the auditory cortex (NCM) of zebra finches, increasing responsiveness to conspecific signals. Conversely, local levels of neuroestradiol are elevated by stimulation with conspecific song (Tremere et al. 2009, Remage-Healey et al. 2010, 2012). These rapid effects are thought to be regulated by non-traditional estrogen receptors on neuronal membranes (Yoder and Vicario 2011). Systemic estrogen can also alter neural function, presumably acting through nuclear estrogen receptors (e.g. ER $\alpha$ ) to produce genomic effects (Maney et al. 2006, Yoder and Vicario 2011). For instance, female white-throated sparrows implanted with estradiol show increased activation of cortical auditory areas in response to conspecific song compared to females implanted with a placebo (Maney et al. 2008). In several species of frog, seasonal changes have 
been documented in the torus semicircularis, a midbrain auditory center with a high density of gonadal hormone receptors (Chakraborty and Burmeister 2010; O'Connell et al. 2011), including fire bellied toads (Bombina bombina; Walkowiak 1980), Cope's gray treefrogs (Hillary 1984) and northern leopard frogs (Rana pipiens; Goense and Feng 2005). In green treefrogs, there are differences in multi-unit responses from the torus semicircularis in mated and unmated females, as well as differences that result from the administration of testosterone (Miranda and Wilczynski 2009a; b). Furthermore, treatment with hCG or estrogen enhances the expression of the immediate early gene egr-1 in the torus semicircularis of female túngara frogs, both to conspecific vocalizations and in silence (Lynch and Wilczynski 2008; Chakraborty and Burmeister 2015). This pattern in response to hormone manipulation recapitulates the ontogenetic pattern in behavior and egr-1 activation in this species (Baugh and Ryan 2010; Baugh et al. 2012)

Estradiol may also be important in modulating auditory function at the periphery, as ER $\alpha$ (estrogen receptor alpha) and aromatase have been found in the inner ear of songbirds (Noirot et al. 2009), although it is currently unknown whether these receptors are present in the auditory end organs of frogs. It is also not currently known whether estrogen receptors (nuclear or nontraditional) are present in the auditory nerve or brainstem of songbirds, so it is unclear what role estrogen action could have on these areas. Gonadal hormone receptors have not typically been found in the auditory forebrain or hindbrain of frogs (Wilczynski and Burmeister 2016). Similarly, some songbird auditory forebrain and midbrain areas appear to be lacking estrogen receptors and aromatase (Maney and Pinaud 2011). Yet, neural function in these areas is altered by systemic estrogen implants, suggesting estrogen-mediated feed-forward effects from the auditory periphery or descending effects from higher-order auditory areas that are sensitive to 
estrogen (Maney and Pinaud 2011). Therefore, even if steroid hormone receptors are not found in the auditory end organs, there may still be efferent modulation that is sensitive to endocrine state.

There are several mechanisms by which hormones have been shown to regulate peripheral auditory processing in fish, which could potentially operate in songbirds and frogs. Plainfin midshipman fish (Porichthys notatus), for example, show enhanced phase-locking in their auditory nerve during the breeding season and this effect can be mimicked with estrogen manipulations (Sisneros et al. 2004; Sisneros 2009). Hair cells also show steroid-dependent sensitivity to tones (Rohmann and Bass 2011). These changes in sensitivity may be due to the addition of hair cells to the saccule during the breeding season (Coffin et al. 2012). Songbirds are capable of regenerating hair cells after damage (Marean et al. 1998; Woolley and Rubel 2002), but it is not yet known whether the addition or replacement of hair cells is a feasible mechanism underlying seasonal plasticity in the avian auditory periphery.

Peripheral auditory plasticity could also be induced by hormone-mediated expression of ion channels in hair cells. For instance, splice variants of voltage-gated calcium and calcium sensitive big potassium (BK) ion channels play an important role in determining the electrical tuning of hair cells in fish (Sugihara and Furukawa 1989; Steinacker and Romero 1992), amphibians (Ashmore 1983), reptiles (Jones et al. 1999) and birds (Fuchs et al. 1988). The expression of splice variants appears to be influenced by estrogen responsive elements involved in transcription of the $\alpha$-subunit (Zhu et al. 2005; Kundu et al. 2007). Seasonal changes in hormone levels could alter estrogen-mediated transcriptional regulation, thereby altering the expression of ion channels in the hair cells. This in turn would alter the functional properties of the hair cells in response to acoustic stimulation. 


\section{CONCLUSIONS AND FUTURE DIRECTIONS}

There are many open questions to be explored about plasticity of the auditory periphery of songbirds and frogs. Although this review has focused primarily on gonadal steroid hormones, there may be other modulators of peripheral auditory function such as adrenal steroid hormones, catecholamines, serotonin, or oxytocin as observed in other taxa (Caras and Remage-Healey 2016; Forlano et al. 2016). Manipulative studies that alter hormone levels both systemically and locally in the periphery at both acute as well as prolonged time frames are needed in a greater number of species and across a wider swath of reproductive time points. It also remains unknown to what extent various receptors are present in auditory end organs and to what degree their expression is plastic across reproductive conditions, which may most easily be addressed through quantitative PCR or transcriptomic approaches, as immunohistochemistry approaches can be challenging in non-model organisms. Finally, the functional consequences of plasticity in peripheral processing are generally unknown. Within-individual approaches may be used to evaluate potential correlations between communication behaviors and individual differences in auditory processing, hormonal state or both. 


\section{LITERATURE CITED}

Anderson T. 2006. Biology of the ubiquitous house sparrow: from genes to populations. New York: Oxford University Press.

Arch VS, Narins PM. 2009. Sexual hearing: The influence of sex hormones on acoustic communication in frogs. Hear Res 252:15-20. doi: 10.1016/j.heares.2009.01.001.

Ashmore J F. 1983 Frequency tuning in a frog vestibular organ. Nature 304, 536-38.

Baugh AT, Ryan MJ. 2010. The development of sexual behaviour in túngara frogs. J Comp Psychol 124:66-80.

Baugh AT, Hoke KL, Ryan MJ. 2012. Development of communication behaviour: receiver ontogeny in túngara frogs and a prospectus for a behavioural evolutionary development. Sci World J, 2012:1-10.

Baugh AT, Bee M, Gall M. 2019. The paradox of hearing at the lek: auditory sensitivity increases after breeding in female gray treefrogs (Hyla chrysoscelis). J Comp Physiol A 205:629-639.

Caras ML, Brenowitz E, Rubel, EW. 2010. Peripheral auditory processing changes seasonally in Gambel's white-crowned sparrow. J Comp Physiol A 196: 581-599.

Caras ML, Remage-Healey L. 2016. Modulation of peripheral and central auditory processing by estrogens in birds. In: Bass AH, Sisneros JA, Popper AN and Fay RR, editors. Hearing and hormones. Springer handbook of auditory research, Vol. 57. New York: Springer Science+Business Media, LLC. p. 77-99.

Catchpole CK, Slater PJB. 2008. Bird song: biological themes and variations. 2nd edn. Cambridge, UK: Cambridge University Press. 
Chakraborty M, Burmeister SS. 2010. Sexually dimorphic androgen and estrogen receptor mRNA expression in the brain of túngara frogs. Hormone Behav 58: 619-627. doi: 10.1016/j.yhbeh.2010.06.013 .

Chakraborty M, Burmeister SS. 2015. Effects of estradiol on neural responses to social signals in female túngara frogs. J Exp Biol 218: 3671-3677.

Coffin AB, Mohr RA, Sisneros JA. 2012 Saccular-specific hair cell addition correlates with reproductive state-dependent changes in the auditory saccular sensitivity of a vocal fish. $\mathrm{J}$ Neurosci 32: 1366-1376.

Forlano PM, Maruska KP, Sisneros JA, Bass AH. 2016. Hormone-dependent plasticity of auditory systems in fishes. In: Bass AH, Sisneros JA, Popper AN and Fay RR, editors. Hearing and Hormones. Springer Handbook of Auditory Research, Vol. 57. New York: Springer Science+Business Media, LLC. p. 15-51.

Fuchs PA, Nagai T, Evans MG. 1988 Electrical tuning in hair cells isolated from the chick cochlea. J Neurosci 8: 2460-67.

Gall MD, Salameh TS, Lucas JR. 2013. Songbird frequency selectivity and temporal resolution vary with sex and season. Proc Roy Soc B 280: 20122296

Gall MD, Wilczynski W. 2015. Hearing conspecific vocal signals alters peripheral auditory sensitivity. Proc Roy Soc B, 282: 20150749.

Gall MD, Wilczynski W. 2016. The effects of call-like masking diminish after nightly exposure to conspecific choruses in green treefrogs (Hyla cinerea). J Exp Biol 219: 1295:1302.

Gall MD, Bee MA, Baugh AT. 2019. The difference a day makes: breeding remodels hearing, hormones and behavior in female Cope's gray treefrogs (Hyla chrysoscelis). Hormones Behav108:62-72 
Goense J, Feng AS. 2005. Seasonal changes in frequency tuning and temporal processing in single neurons in the frog auditory midbrain. J Neurobiol 65: 22-36.

Hall IC, Woolley SMN, Kelley DB. 2016. Sex differences and endocrine regulation of auditoryevoked, neural responses in African clawed frogs (Xenopus). J Comp Physiol A 202: 1734. doi:10.1007/s00359-015-1049-9.

Harvey LA, Propper CR, Woodley SK, Moore MC. 1997. Reproductive endocrinology of the explosively breeding desert spadefoot toad, Scaphiopus couchii. Gen Comp Endocrinol 105: 102-113.

Hegner RE, Wingfield JC. 1986a. Behavioral and endocrine correlates of multiple brooding in the semicolonial house sparrow Passer domesticus. I. males. Hormone Behav 20: 294312.

Hegner RE, Wingfield JC. 1986b. Behavioral and endocrine correlates of multiple brooding in the semicolonial house sparrow Passer domesticus. II. Females. Hormone Behav 20: 313326.

Hegner RE, Wingfield JC. 1986c. Gonadal development during autumn and winter in house sparrows. Condor 88:269-278.

Henry KS, Lucas JR. 2009. Vocally-correlated seasonal auditory variation in the house sparrow (Passer domesticus). J Exp Biol 212: 3817-3822.

Hillary CM. 1984. Seasonality of two midbrain auditory responses in the treefrog, Hyla chrysoscelis. Copeia 1984: 844-852.

Itoh M, Ishii S. 1990. Changes in plasma levels of gonadotropins and sex steroids in the toad, Bufo japonicus, in association with behavior during the breeding season. Gen Comp Endocrinol 80: 451-464. 
Jones EM, Gray-Keller M, Fettiplace R. 1999. The role of Ca+2-activated K+ channel spliced variants in the tonotopic organization of the turtle cochlea. J Physiol 518: 653-665.

Kundu P, Alioua A, Stefani E, Toro L. 2007 Regulation of mouse Slo gene expression: multiple promoters, transcription start sites, and genomic action of estrogen. J Biol Chem 282: $27478-27492$.

Kroodsma DE, Miller EH. 1982. Acoustic communication in birds, Vol 2. New York: Academic Press.

Lattin CR, Stabile FA, Carson RE. 2017. Estradiol modulates neural response to conspecific and heterospecific song in female house sparrows: An in vivo positron emission tomography study. PLoS One: e0182875.

Lucas JR, Freeberg TM, Krishnan A, Long GR. 2002. A comparative study of avian auditory brainstem responses: correlations with phylogeny and vocal complexity, and seasonal effects. J Comp Physiol A 188: 981-992.

Lucas JR, Freeberg TM, Long GR, Krishnan A. 2007. Seasonal variation in avian auditory evoked responses to tones, a comparative analysis of Carolina chickadees, tufted titmice, and white-breasted nuthatches. J Comp Physiol A 192: 201-215.

Lynch KS, Wilczynski W. 2005. Gonadal steroid fluctuations in a tropically breeding female anuran. Gen Comp Endocrinol 43:51-56.

Lynch KS, Rand AS, Ryan MJ, Wilczynski W. 2005. Plasticity in female mate choice associated with changing reproductive states. Anim Behav 69:689-699

Lynch KS, Wilczynski W. 2008. Reproductive hormones modify reception of species- typical communication signals in a female anuran. Brain Behav Evol 71:143-150. doi: $10.1159 / 000111460$ 
Maney DL, Cho E, Goode CT. 2006. Estrogen-dependent selectivity of genomic responses to birdsong. E J Neurosci 23: 1523-1529. doi:10.1111/j.1460-9568.2006.04673.x

Maney DL, Goode CT, Lange HS, Sanford SE, Solomon BL. 2008. Estradiol modulates neural responses to song in a seasonal songbird. J Comp Neurol 511: 173-186.

Maney DL, Pinaud R. 2011. Estradiol-dependent modulation of auditory processing and selectivity in songbirds. Front Neuroendocrin 32: 287-303.

Marean GC, Burt JM, Beecher MD, Rubel EW. 1998. Auditory perception following hair cell regeneration in European starling (Sturnus vulgaris): frequency and temporal resolution. J Acoust Soc Am 103: 3567-3580.

Miranda JA, Wilczynski W. 2009a. Sex differences and androgen influences on midbrain auditory thresholds in the green treefrog, Hyla cinerea. Hear Res 252:79-88. doi: 10.1016/j.heares.2009.04.004.

Miranda JA, Wilczynski W. 2009b. Female reproductive state influences the auditory midbrain response. J Comp Physiol A 195: 341-349. doi: 10.1007/s00359-008-0410-7.

Noirot IC, Adler HJ, Cornil CA, Harada N, Dooling RJ, Balthazart J, Ball GF. 2009. Presence of aromatase and estrogen receptor alpha in the inner ear of zebra finches. Hear Res 252: $49-55$.

Penna M, Narins PM. 1989. Effects of acoustic overstimulation on spectral and temporal processing in the amphibian auditory nerve. J Acoust Soc Am 85:1617-1629

O’Connell LA, Ding JH, Ryan MJ, Hofmann HA. 2011. Neural distribution of the nuclear progesterone receptor in the túngara frog, Physalaemus pustulosus. J Chem Neuroanat 41: 137-147. doi: 10.1016/j.jchemneu.2011.01.002. 
Remage-Healey L, Coleman ME, Oyama RK, Schlinger BA. 2010. Brain estrogens rapidly strengthen auditory encoding and guide song preference in a songbird. Proc Natl Acad Sci USA 107:3852-7

Remage-Healey L, Dong SM, Chao A, Schlinger BA. 2012. Sex-specific, rapid neuroestrogen fluctuations and neurophysiological actions in the songbird auditory forebrain. J Neurophysiol 107:1621-31.

Riley GM. 1936. Light regulation of sexual activity in the male house sparrow (Passer domesticus). Proc Soc Exp Biol Med 34:331-332.

Rohmann KN, Bass AH. 2011. Seasonal plasticity of auditory hair cell frequency sensitivity correlates with plasma steroid levels in vocal fish. J Exp Biol 214: 1931-1942.

Ryan, M.J. 2001. Anuran Communication. Smithsonian Institution Press. Washington, D.C. Simmons DD, Lohr R, Wotring H, Burton MD, Hooper RA, Baird RA. 2014. Recovery of otoacoustic emissions after high-level noise exposure in the American bullfrog. J Exp Biol 217:1626-1636. https ://doi.org/10.1242/jeb.09009

Sisneros JA, Forlano PM, Deitcher DL, Bass AH. 2004. Steroid-dependent auditory plasticity lead to adaptive coupling of sender and receiver. Sci 305: 404-407.

Sisneros JA. 2009. Adaptive hearing in the vocal plainfin midshipman fish, getting in tune for the breeding season and implications for acoustic communication. Int Zool 4: 33-42.

Steinacker A, Romero A. 1992. Voltage-gated potassium current and resonance in toadfish saccular hair cells. Brain Res 574: 229-36.

Sugihara I, Furukawa T. 1989. Morphological and functional aspects of two different types of hair cells in the goldfish sacculus. J Neurophysiol 62:1330-43. 
Tremere LA, Jeong JK, Pinaud R. 2009. Estradiol shapes auditory processing in the adult brain by regulating inhibitory transmission and plasticity-associated gene expression. J Neurosci 29:5949-5963

Velez A. Gall MD, Lucas JR. 2015. Seasonal plasticity in auditory processing of the envelope and temporal fine structure of sounds in three songbirds. Anim Behav 103: 53-63.

Walkowiak W. 1980. The coding of auditory signals in the torus semicircularis of the firebellied toad and the grass frog: Responses to simple stimuli and to conspecific calls. J Comp Physiol 138: 131-148. doi: 10.1007/BF00680437 .

Webb JF, Fay RR, Popper AN. 2008. Fish bioacoustics. New York: Springer-Verlag. Wilczynski W, Burmeister SS. 2016. Effects of steroid hormones on hearing and communication in frogs. In: Bass AH, Sisneros JA, Popper AN and Fay RR, editors. Hearing and hormones. Springer handbook of auditory research, Vol. 57. New York: Springer Science+Business Media, LLC. p. 53-75.

Woolley SMN, Rubel EW. 2002. Vocal memory and learning in adult Bengalese finches with regenerated hair cells. J Neurosci 22:7774-7787.

Yoder KM, Vicario DS. 2011. To modulate and be modulated: estrogenic influences on auditory processing of communication signals within a socio-neuro-endocrine framework. Behav Neurosci 126: 17-28.

Zelick R, Narins PM. 1985. Temporary threshold shift, adaptation, and recovery characteristics of frog auditory nerve fibers. Hear Res 17:161-176

Zhang D, Cui J, Tang Y. 2012. Plasticity of peripheral auditory frequency sensitivity in Emei music frog. PLoS ONE 7: e45792. https://doi.org/10.1371/journal.pone.0045792 
Zhu N, Eghbali M, Helguera G, Song M, Stefani E, Toro L. 2005. Alternative splicing of Slo channel gene programmed by estrogen, progesterone and pregnancy. FEBS Lett 579: $4856-4860$. 
Figure 1. Effects of sex and season on frequency selectivity and temporal resolution in the house sparrow (Passer domesticus; N=36 total, 9 per group). Frequency selectivity was measured using a notched-noise protocol to determine auditory filter bandwidth. Note that bandwidths are averaged across center frequencies $(\mathrm{CF}=2,3$, or $4 \mathrm{kHz})$ and that frequency selectivity is inversely related to filter bandwidth. Temporal resolution was measured with a paired click paradigm (inter-click intervals $0.7-25 \mathrm{~ms}$ ). ABR (auditory brainstem response) recovery is the amplitude of the onset response to the second click divided by the amplitude of the onset response to a single click. Males and females did not differ in the fall and males did not change across the seasons. However, female frequency selectivity increased and temporal resolution decreased in the spring, leading to a difference between males and females in the spring. Note that data are averaged across all inter-click intervals. LSMEANS ( \pm S.E.) were generated in SAS 9.2. From Gall et. al 2013.

Figure 2. (a) Frequency selectivity and (b,c) temporal resolution in house sparrows (Passer domesticus $)$ treated with either a placebo or hormone implant $(\mathrm{N}$ total $=36, \mathrm{~N}$ per group $=9)$. Frequency selectivity was measured using a notched-noise protocol to determine auditory filter bandwidth. Note that bandwidths are averaged across center frequencies $(\mathrm{CF}=2,3$, or $4 \mathrm{kHz})$ and that frequency selectivity is inversely related to filter bandwidth. Temporal resolution was measured with a paired click paradigm (inter-click intervals $0.7-25 \mathrm{~ms}$ ). ABR (auditory brainstem response) recovery is the amplitude of the onset response to the second click divided by the amplitude of the onset response to a single click. (a) We did not find an effect of sex on 
frequency selectivity plasticity. Pre-treatment animals in the two treatment conditions did not differ. Animals with a placebo implant did not show plasticity in their frequency resolution (females: $\mathrm{F}_{1,182}=0.68, \mathrm{p}=0.41$, males: $\mathrm{F}_{1,182}=0.68 \mathrm{p}=0.41$ ), but animals given a hormone implant showed enhanced frequency resolution after three weeks (females: $F_{1,182}=5.7, p=0.018$, males: $F_{1,182}=3.74 p=0.04$ ). (b) Similarly, neither sex exhibited plasticity in temporal resolution when given a placebo implant (females: $F_{1,665}=0.98, p=0.32$, males: $F_{1,665}=0.3 p=$ 0.59). (c) Females, but not males, showed diminished temporal resolution when given a hormone implant (females: $F_{1,665}=21.7, p<0.001$, males: $\left.F_{1,665}=1.62 p=0.20\right)$. LSMEANS $( \pm$ S.E. $)$ were generated in SAS 9.2. 

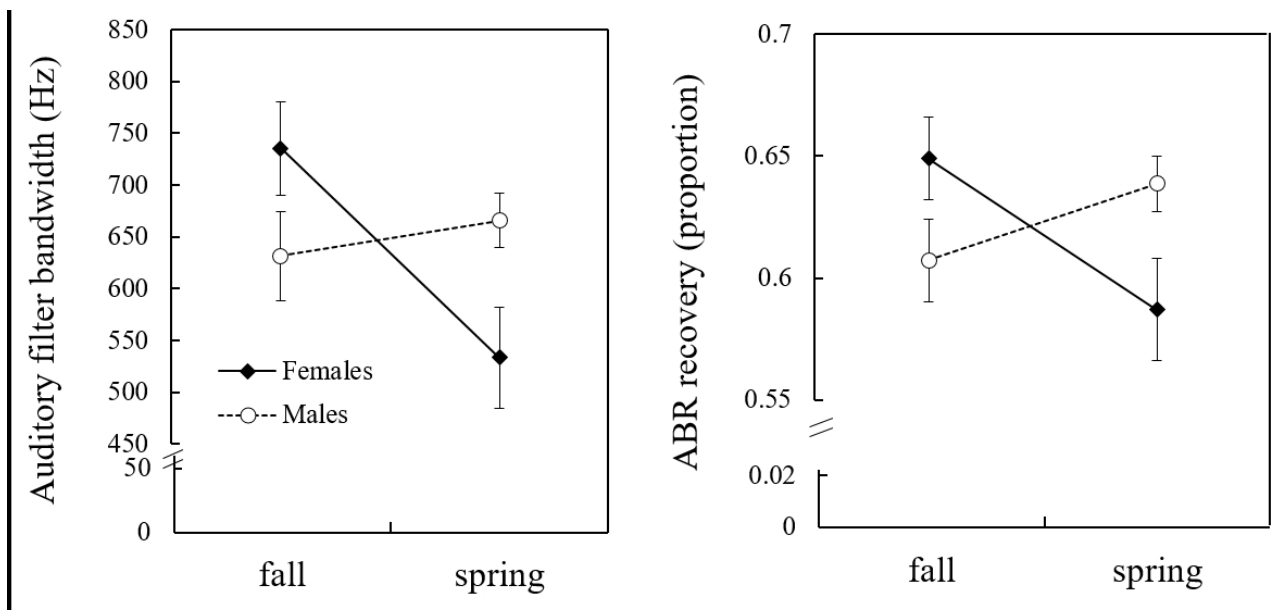

Figure 1. Effects of sex and season on frequency selectivity and temporal resolution in the house sparrow (Passer domesticus, $\mathrm{N}=36$ total, 9 per group). Frequency selectivity was measured using a notched-noise protocol to determine auditory filter bandwidth. Note that bandwidths are averaged across center frequencies $(\mathrm{CF}=2,3$, or $4 \mathrm{kHz})$ and that frequency selectivity is inversely related to filter bandwidth. Temporal resolution was measured with a paired click paradigm (inter-click intervals 0.7-25 ms). ABR recovery is the amplitude of the onset response to the second click divided by the amplitude of the onset response to a single click. Males and females did not differ in the fall and males did not change across the seasons. However, female frequency selectivity increased and temporal resolution decreased in the spring, leading to a difference between males and females in the spring. Note that data are averaged across all inter-click intervals. LSMEANS ( \pm S.E.) were generated in SAS 9.2. From Gall et. al 2013.

$$
203 \times 93 \mathrm{~mm}(150 \times 150 \mathrm{DPI})
$$



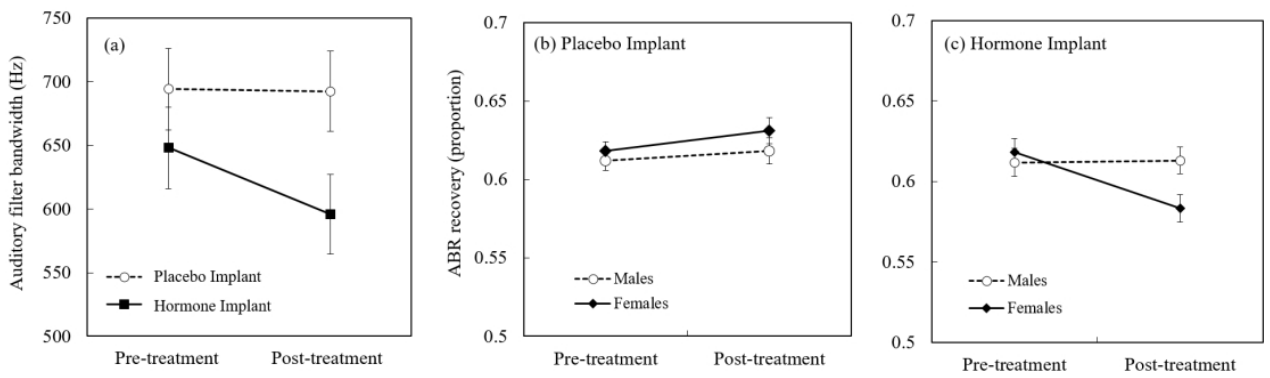

Figure 2. (a) Frequency selectivity and $(b, c)$ temporal resolution in house sparrows (Passer domesticus) treated with either a placebo or hormone implant $(\mathrm{N}$ total $=36, \mathrm{~N}$ per group $=9$ ). Frequency selectivity was measured using a notched-noise protocol to determine auditory filter bandwidth. Note that bandwidths are averaged across center frequencies $(\mathrm{CF}=2,3$, or $4 \mathrm{kHz})$ and that frequency selectivity is inversely related to filter bandwidth. Temporal resolution was measured with a paired click paradigm (inter-click intervals 0.7-25 $\mathrm{ms}$ ). ABR (auditory brainstem response) recovery is the amplitude of the onset response to the second click divided by the amplitude of the onset response to a single click. (a) We did not find an effect of sex on frequency selectivity plasticity. Pre-treatment animals in the two treatment conditions did not differ. Animals with a placebo implant did not show plasticity in their frequency resolution (females: $F 1,182=0.68$, $p=0.41$, males: $F 1,182=0.68 p=0.41$, but animals given a hormone implant showed enhanced frequency resolution after three weeks (females: $F 1,182=5.7, p=0.018$, males: $F 1,182=3.74 p=0.04$ ). (b) Similarly, neither sex exhibited plasticity in temporal resolution when given a placebo implant (females: $F 1,665=0.98, p=0.32$, males: $F 1,665=0.3 p=0.59$ ). (c) Females, but not males, showed diminished temporal resolution when given a hormone implant (females: $F 1,665=21.7, p<0.001$, males: $F 1,665=$ $1.62 \mathrm{p}=0.20$ ). LSMEANS ( \pm S.E.) were generated in SAS 9.2.

$336 \times 113 \mathrm{~mm}(150 \times 150 \mathrm{DPI})$ 
Table 1. Pre-treatment and post-treatment plasma testosterone (male) and estradiol (female) levels in house sparrows $\left(\mathrm{ng} \mathrm{ml}^{-1}\right)$. All plasma samples were collected between 1100 and 1300 EST. All animals were housed on a long day (14:10) light cycle. Values given are mean \pm S.E.

\begin{tabular}{cccccc}
\hline & Pre-treatment & Post-treatment & $\mathrm{t}$ & $\mathrm{p}$ & $\mathrm{n}$ \\
\hline Males (Placebo) & $2.01 \pm 0.27$ & $4.97 \pm 0.84$ & 2.85 & $\mathbf{0 . 0 2 2}$ & 9 \\
Males (T) & $2.14 \pm 0.29$ & $33.77 \pm 4.26$ & 7.68 & $<\mathbf{0 . 0 0 1}$ & 9 \\
Females (Placebo) & $0.23 \pm .08$ & $0.25 \pm 0.11$ & 0.24 & 0.82 & 9 \\
Females (E2) & $0.21 \pm 0.07$ & $0.60 \pm 0.11$ & 2.92 & $\mathbf{0 . 0 1 9}$ & 9 \\
\hline
\end{tabular}

$\mathrm{T}=$ Testosterone, $\mathrm{E} 2=$ Estradiol 